\title{
A PESSOA CEGA E A INCLUSÃO: UM OLHAR A PARTIR DA PSICOLOGIA HISTÓRICO-CULTURAL
}

\author{
Miriam Cristina Frey de Lira* \\ LuCIANE Maria SCHLINDWEIN ${ }^{* *}$
}

\begin{abstract}
RESUMO: Neste trabalho discutimos a inclusão do aluno com diferenças visuais considerando suas lembranças escolares. Foram coletados depoimentos orais de três alunos com diferenças visuais matriculados em cursos de graduação com o intuito de compreender como as relações estabelecidas ao longo do percurso escolar podem ter auxiliado esses alunos a vencerem o estigma da exclusão. As análises aqui apresentadas apóiam-se nos aportes teóricos da psicologia histórico-cultural, segundo a qual o psiquismo humano se constitui socialmente, trazendo em si a marca da cultura em que o homem está imerso. Os resultados apresentados indicam que a história escolar desses alunos decorreu em meio a muitas dificuldades, que foram sendo superadas na medida em que esses sujeitos passam de uma situação de dependência para uma situação de controle maior sobre suas próprias vidas, com papéis sociais mais definidos e valorizados em suas comunidades.
\end{abstract}

Palavras-chave: Inclusão. Psicologia histórico-cultural. Pessoa cega.

\section{THE BLIND PERSON AND THE INCLUSION: \\ A CULTURAL-HISTORICAL PSYCHOLOGY VIEW}

ABSTRACT: In this work we discuss the inclusion of the students with visual differences considering his memories about school time. We collect verbal testimonies of three academic students with visual differences. Our intention was to understand as the relationships

Mestre em Educação e docente da Universidade do Vale do Itajaí (Univali). E-mail: miriamlira@univali.br

** Doutora em Educação e docente da Universidade do Vale do Itajaí (UNIVALI). E-mail: lucmas@uol.com.br

Cad. Cedes, Campinas, vol. 28, n. 75, p. 171-190, maio/ago. 2008 
which were established throughout the school time may have helped these students to surpass the stigma of the exclusion. The analyses presented here are based on the historic-cultural psychology. According to this theory, the human psyche is constituted socially, bringing inside itself the mark of the culture in which the man is immersed. The presented results indicate that in their school history these students have passed by many difficulties that go from the lack of suitable materials, to the isolation because of the prejudice that the blind person or with other visual limitations have to daily face. The presented results indicate more that the pertaining to school history of these pupils elapsed in way to many difficulties, that had been being surpassed in the measure where these citizens pass of a situation of dependence for a situation of bigger control on its proper lives, with defined and valued social papers in its communities.

Key words: Inclusion. Historic-cultural psychology. Blind person.

\section{O contexto do trabalho}

$\mathcal{E}$ ste trabalho, parte da dissertação de mestrado (Lira, 2005), discute a problemática da inclusão de pessoas cegas ou com baixa visão, a partir de seus depoimentos sobre suas trajetórias escolares. Foram analisados os depoimentos de três acadêmicos com diagnóstico de baixa visão e cegueira regularmente matriculados no ensino superior de uma universidade brasileira. As entrevistas foram gravadas e transcritas e, por meio da análise de conteúdo, as narrativas dos sujeitos sobre seus percursos escolares foram analisadas. Para facilitar a identificação dos sujeitos e a localização de suas falas no decorrer das análises, cada sujeito foi identificado pela letra $S$ seguida dos números 1, 2 e 3 correspondentes à ordem em que foram realizados os depoimentos. As falas dos depoimentos foram organizadas em parágrafos, de acordo com a atribuição de significados. Cada parágrafo, na transcrição dos depoimentos, está identificado por um número seqüencial que permite ao leitor identificálos no texto. Por exemplo, o código S1P2 refere-se ao depoimento do sujeito identificado com o número 3 , no parágrafo 26 . O recorte aqui apresentado diz respeito à percepção dos entrevistados sobre sua característica sensorial e o reflexo desta nas relações com os outros.

Refletir sobre a escolaridade de alunos com diferenças visuais é buscar compreender como esses alunos vêm se constituindo ao longo 
do processo de inclusão. Parte-se da premissa de que uma diferença visual não representa, em si mesma, alterações nas possibilidades de aprendizagem da criança, na sua capacidade de estabelecer relações com os outros, com objetos e situações que acontecem ao seu redor. Como qualquer outra, a criança com diferenças visuais precisa de oportunidades, de convivência com seus pares, de forma que possa aprender a se relacionar com o mundo. É no contexto cultural que a criança aprende, desenvolve os sentimentos em relação a si mesma, as atitudes em relação aos outros e a familiaridade com o meio ambiente.

Consideramos que as necessidades especiais não são propriedades ou exigências dos seres humanos, nem nascem com eles, mas se originam de um processo de produção material e social. O elemento biológico não se constitui em único determinante para as necessidades humanas. As necessidades e as habilidades são produzidas no processo histórico. Embora a criança possa ser privada de um elemento biológico, físico e/ou sensorial, a necessidade de apropriar-se da realidade não só é síntese de uma atividade real e de uma capacidade desenvolvida, é produto social e histórico (Freire, 1998).

A escola pode auxiliar a enfrentar as dificuldades impostas pela diferença visual em uma sociedade essencialmente visual. No espaço escolar, as questôes relacionadas a preconceitos, estigmas e mitos podem ser superadas, desde que seus integrantes, professores, alunos, funcionários e pais, discutam e analisem tais questôes (Gil, 2000). A diminuição ou impossibilidade de acessar informações através de um canal sensorial da importância da visão faz com que a percepção da realidade por uma pessoa cega ou com baixa visão seja diferente da das pessoas que enxergam (Ocahita \& Rosa, 1995; Martín \& Bueno, 1997; Amiralian, 1997). As experiências do indivíduo podem ser diminuídas, já que a maioria das informações na nossa sociedade necessita da visão para serem acessadas, mas o organismo dispõe de outras vias que podem suprir ou complementar a via visual. Uma orientação adequada é fundamental, principalmente nos primeiros anos de vida do ser humano e, especialmente, nos períodos iniciais de escolarização.

Os processos superiores do pensamento infantil surgem no processo de interação com o meio social circundante (Vigotski, 1997). O autor afirma que as dificuldades derivadas do defeito (no caso a dificuldade de ver) originam estímulos para a formação de outras formas 
A pessoa cega e a inclusão: um olhar a partir da psicologia histórico-cultural

de funcionamento e esses estímulos provêm das relaçôes sociais, das necessidades, dos motivos e da vontade e podem conduzir a processos edificadores e equilibradores no desenvolvimento e na conduta dos indivíduos que, por sua vez, podem se consolidar em desenvolvimento pessoal (Vigotski, 1989). A escola pode ser, portanto, um espaço privilegiado de aprendizagem também para a criança cega ou com baixa visão. "Importa que a educação seja orientada em direção à plena validez social e a considere como um ponto real e determinante, e não que se nutra da idéia de que o cego está condenado a menos valia" (Vigotski, 1989, p. 54).

Os sujeitos entrevistados para esta pesquisa não freqüentaram nenhuma instituição especializada nos primeiros anos de suas escolarizaçôes, nem foram preparados para o ingresso na escola, nem a escola foi preparada para o ingresso dos mesmos, como é indicado por alguns autores (Gil, 2000; Martín \& Bueno, 2003). Seus percursos foram marcados por situações difíceis, que os levaram a abandonar a escola em diferentes momentos de suas trajetórias. Entretanto, esse fato não os impediu de avançarem na sua escolarização, chegando ao ensino superior, situação atingida atualmente por somente $9 \%$ dos jovens brasileiros (fonte disponível em: http://www.mec.gov.br).

De acordo com os relatos dos envolvidos na pesquisa, a condição de ser o único com determinadas características no espaço escolar resultava em uma espécie de descaso da instituição com a situação vivida pelo aluno cego ou de baixa visão, o que reforçava o sentimento de medo e vergonha relatado pelos mesmos:

"Eu comecei com quatro aninhos e meio pra cinco na pré-escola. Fiquei lá até os sete anos e fui para a primeira série. Não tinha ninguém com deficiência visual na escola, eu era a única, era pequeninha, precisava de material adaptado, mas não tinha, não existia. Eu lembro que enxergava bem pouquinho, lembro que me batia nas carteiras. Eu não conseguia acompanhar o pessoal devido ao problema de visão, não tinha adaptação de material de jeito nenhum, nada" (S1P2).

As expectativas do aluno com relação à escola são muitas vezes frustradas, não por incompetência ou falta de capacidade intelectual, mas por negligência do sistema educacional ou da própria escola que não utiliza os recursos didáticos adequados para a facilitação do processo ensino-aprendizagem. 
A questão da pessoa cega na história

Por um longo período da história os indivíduos com diferenças visuais, ao lado de outras pessoas consideradas como "deficientes", viveram um duro processo de desvalorização e de exclusão social. Esta diferença, em especial a cegueira, sempre foi tida como um estigma, uma marca diferencial que pressupunha desgraça, castigo e morte.

A preocupação com a educação de pessoas cegas surgiu no século XVI, com Girolínia Cardono, médico italiano que testou a possibilidade do aprendizado de leitura através do tato. Peter Pontamus, Fleming (cego) e o padre Lara Terzi escreveram os primeiros livros sobre a educaçáo das pessoas cegas (Bruno \& Mota, 2001).

As primeiras tentativas para a criação de métodos que permitissem aos cegos o acesso à linguagem escrita utilizavam fundição de letras em metal, caracteres recortados em papel, alfinetes de diversos tamanhos pregados em almofadas, mas estes só permitiam a leitura de pequenos textos, enquanto a escrita era impossível de se realizar (Belarmino, 1996).

A partir deste período, as idéias difundidas foram ganhando força até que, em 1784, surgiu em Paris, criada por Valentin Haüy, a primeira escola para cegos: Instituto Real dos Jovens Cegos, onde se ensinava a ler através da impressão de textos em papel muito forte, que permitia dar relevo às letras. No século XIX, proliferaram na Europa e nos Estados Unidos escolas com a mesma proposta educacional. Em 1819, ingressa, no Instituto Real dos Jovens Cegos, o jovem Louis Braille, que mais tarde viria a desenvolver um sistema com caracteres em relevo para escrita e leitura de cegos - o sistema Braille. Com a utilização do método Braille, a educação da pessoa cega teve um grande desenvolvimento.

No Brasil, o atendimento às pessoas com diferenças visuais iniciou-se com a fundação do Imperial Instituto de Meninos Cegos, na cidade do Rio de Janeiro, em 1854, pelo Imperador D. Pedro II. José Álvares de Azevedo, jovem brasileiro que estudou no Instituto Real dos Jovens Cegos, em Paris, foi o responsável por trazer ao país a idéia e a iniciativa da primeira criação de uma escola para o atendimento de pessoas cegas (Bueno, 1999).

Em 1891, com a queda da Monarquia e a proclamação da República, o Imperial Instituto de Meninos Cegos passou a receber a denominação de Instituto Benjamin Constant (IBC), em homenagem ao 
republicano Benjamin Constant Botelho de Magalhães, que dirigiu o educandário de 1869 até 1889 . O Instituto foi o responsável pela educação dos indivíduos cegos até 1926, quando foi inaugurado o Instituto São Rafael, em Belo Horizonte, seguindo-se em 1927, na cidade de São Paulo, o Instituto Profissional para Cegos Padre Chico.

O Censo de 2000 revelou que $14,5 \%$ da população brasileira apresentam, pelo menos, uma das deficiências investigadas pela pesquisa. A maior proporção se encontra no Nordeste $(16,8 \%)$, e a menor, no Sudeste $(13,1 \%)$. Em 2000, existiam 148 mil pessoas cegas e 2,4 milhões com grande dificuldade de enxergar. Do total de cegos, 77.900 eram mulheres e 70.100 homens. A região Nordeste, apesar de ter população inferior ao Sudeste, concentrava o maior número de pessoas cegas: 57.400 cegos no Nordeste contra 54.600 no Sudeste. São Paulo é o estado com o maior número de cegos (23.900), seguido da Bahia (15.400). No aspecto educacional, em 2000, a taxa de alfabetização das pessoas com 15 anos ou mais de idade era de $87,1 \%$. Já entre os que apresentam algum tipo de limitação ou deficiência, era de 72,0\% (Neri, 2003).

Ao se tratar especificamente da educação da pessoa com diferenças visuais, pode-se dizer que a falta de visão é percebida, a priori, como ponto frágil e vulnerável, causando curiosidade, piedade, surpresa e admiração, de forma que a pessoa é vista como dependente, precisando ser guiada, protegida e amparada.

No contexto familiar, por exemplo, as pessoas não sabem o que é ser cego, o que é ser alguém com uma capacidade visual limitada e não conhecem as formas de interação desses com o meio. De forma semelhante, os professores que recebem alunos cegos ou com baixa visão em sala de aula, na sua maioria, têm apenas informações teóricas sobre a questão e não conhecem as potencialidades e possibilidades deste aluno. Há uma tendência cultural da pessoa vidente considerar este indivíduo como limitado, e, conseqüentemente, incapaz ou deficiente.

\section{A psicologia histórico-cultural e a história dos cegos}

Vigotski ${ }^{1}$ (1997) realiza uma análise histórica dos pontos de vista dominantes sobre a psicologia do cego a partir de uma idéia central: a cegueira não é somente um defeito, uma debilidade, mas uma fonte 
de atitudes, de força criativa, já que cria uma nova e peculiar configuração da personalidade. De acordo com o autor, a primeira etapa é a mística e predominou durante a Antiguidade, a Idade Média e parte da História Moderna; a segunda etapa, denominada por ele de biológica, predominou no século XVIII e a terceira etapa, científica ou sociopsicológica, nasceu com as reflexões surgidas da psicologia social (especialmente os estudos de Adler).

Durante a primeira etapa, que ainda sobrevive em lendas, contos e provérbios, a cegueira sugere uma enorme infelicidade, medo, respeito e o tratamento do cego como indefeso e abandonado. Mas, ao mesmo tempo, a crença de que a cegueira desenvolve na pessoa forças místicas superiores que lhe davam uma visão espiritual substitutiva da visão que perdeu. Homero era cego e conta-se que Demócrito cegou a si mesmo para dedicar-se à filosofia porque o dom filosófico se intensificava com a cegueira; o Talmud se refere a cegos como "pessoas com abundância de luz", e nos ditos populares se considerava o cego como uma pessoa com "luz interior". Finalmente, no cristianismo, se incluiu o cego entre "os últimos na Terra" que se converteriam "nos primeiros no Paraíso".

No século XVIII configura-se um novo posicionamento com relação à cegueira: no lugar da mística toma lugar a ciência e, no lugar do préjulgamento, a experiência e o estudo. Como conseqüência dessa nova compreensão da cegueira, iniciou-se a educação da pessoa cega, incorporando-a à vida social e à cultura. Apesar desses avanços, Vigotski discute a teoria da "substituição dos órgãos dos sentidos", segundo a qual a natureza havia dotado os cegos de um "sexto sentido" que interpretava erroneamente alguns feitos da vida dos cegos. A partir de investigaçóes da época, Vigotski mostra que não existe uma "compensação fisiológica direta do defeito da visão, mas uma compensação sociopsicológica que segue um curso muito complexo e indireto, sem substituir a função suprimida nem ocupar o lugar do órgão insuficiente" (Vygotski, 1997, p.101).

Apesar da ingenuidade da concepção biológica, deu-se um grande passo sobre a compreensão da cegueira. A criação do sistema Braille permitiu aos cegos uma participação maior na vida social e cultural. "Um ponto do alfabeto Braille fez mais pelos cegos do que milhares de benfeitores; a possibilidade de ler e escrever resultou mais importante que 'o sexto sentido' e a sutileza do tato e do ouvido” (p. 102). As dificuldades 
que a cegueira cria ao cego para participar da vida social geram o conflito e as tendências a uma supercompensação, que vão possibilitar a formação de uma personalidade de pleno valor social.

Após analisar numerosas investigações realizadas em sua época sobre as percepções, a memória e a atenção dos cegos, além de depoimentos de pessoas cegas sobre suas emoções, sentimentos e fantasias, Vigotski (1997, p. 106) define uma regra fundamental para a psicologia dos cegos:

(...) o todo não pode ser explicado nem compreendido por suas partes, mas as partes podem ser compreendidas com base no todo. A psicologia dos cegos pode ser construída, não da soma de peculiaridades singulares, de desvios parciais, de traços isolados de uma ou outra função, mas estas mesmas particularidades e desvios se tornam compreensíveis somente quando partimos de um objetivo vital único e integral, da linha diretriz do cego, e determinamos o lugar e significado de cada particularidade e traço isolado neste todo e em vinculação com ele, quer dizer, com todos os traços restantes.

Para o autor, "o mais característico do cego é a contradição entre a relativa impotência em relação ao espaço e a possibilidade através da linguagem de uma comunicação completa e absolutamente adequada e de uma compreensão mútua com os videntes" (p. 107). A força motriz fundamental da compensação da cegueira é a linguagem - o signo - para o que não tem limites naturais.

No reino animal, a criatura cega é mais indefesa que a surda, pois as informações da natureza são mais visuais que auditivas. No entanto, se no aspecto biológico o cego perdeu mais que o surdo, no homem, no qual se apresentam em primeiro grau as funçóes sociais e técnicas, o cego, como personalidade, como unidade social, tem a linguagem e junto com ela a possibilidade da validez social: "a palavra vence a cegueira" (Vygotski, 1997, p. 108).

Para Vigotski (ibid., p. 112), “(...) a educação da criança cega deve ser organizada como a educação da criança capaz de um desenvolvimento normal (...)".

Segundo Van Der Verr e Valsiner (1996, p. 73), o interesse de Vigotski pelos problemas da defectologia ${ }^{2}$ se evidencia a partir de sua primeira publicação na área em 1924, que refletia o trabalho que realizava 
no subdepartamento de educação de crianças defeituosas ${ }^{3}$ no Narkowps (Comissariado da Educação).

Uma das características desses estudos é a ênfase na educação social de crianças com "deficiência" e no potencial da criança para o desenvolvimento normal. Vigotski (1989) afirmava que todas as deficiências afetavam antes as relaçôes sociais das crianças e não suas interaçôes diretas com o ambiente. O defeito manifestava-se como uma mudança na situação social da criança. Pais, parentes e amigos tratariam a criança deficiente de uma maneira diferente das demais.

Qualquer defeito, seja a cegueira, a surdez ou a deficiência mental inata, influi, sobretudo, nas relações com as pessoas. Inclusive na família, à criança diferente é dado um tratamento exclusivo, inabitual, distinto do que se dá aos outros, e isto não ocorre somente nas famílias em que esta criança é uma carga pesada e um castigo, mas também quando é rodeado de um amor duplicado ou uma atenção superprotetora que o separa dos demais. Isto evidencia as confissóes reflexivas dos próprios cegos e surdos, como a observação cotidiana, muito simples, da vida das crianças com defeitos e os dados da análise científica e psicológica. (Vygotski, 1989, p. 53)

Caberia à defectologia dominar o conhecimento sobre os processos de desenvolvimento das crianças afetadas por uma determinada característica, descobrir as leis da diversidade (idem, ibid., p. 13). O fundamental, afirmava Vigostki, era tratar e compreender as deficiências como conseqüências sociais e não como um fato estritamente biológico.

Para Vigotski (1997) as leis que regem o desenvolvimento do aluno com algum dano físico ou mental e do aluno considerado normal são as mesmas. Não existem diferenças básicas no impulso para o desenvolvimento da criança, seja ela cega ou vidente, surda ou ouvinte, já que as forças do desenvolvimento são dinâmicas e buscam, através da compensação, uma superação de um estado de insegurança e de inferioridade que a condição da criança impóe. Porém, as regularidades, em um e outro caso, se expressam de maneira peculiar. É preciso observar sempre dois focos: as leis comuns do desenvolvimento infantil e, depois, as peculiaridades referentes ao aluno com história de deficiência. Neste sentido, torna-se interessante analisar as funções elementares e as funções psicológicas superiores. 
O desenvolvimento incompleto das funções elementares, ${ }^{4}$ geralmente, é conseqüência direta de uma deficiência, enquanto o desenvolvimento incompleto das funçōes psicológicas superiores ${ }^{5}$ surge como um fenômeno secundário, produzido, que se une à deficiência. É, então, essencial diferenciar o que é primário (patológico) e o que é secundário (social), não só para a compreensão teórica, mas, principalmente, para direcionar a prática educativa com tais alunos. Vigotski (1997, p. 222) afirma que:

(...) os processos elementares, inferiores, são os menos educáveis, os menos dependentes em relação a sua estrutura das influências externas, do desenvolvimento social da criança, isto por uma parte. Por outra parte, estes sintomas primários que nascem diretamente do próprio núcleo do defeito, se acham tão intimamente ligados a este núcleo que não se consegue vencê-los enquanto não for eliminado o próprio defeito. E, como na maioria dos casos, a eliminação do defeito é algo praticamente impossível, o resultado natural é que também a luta contra os sintomas primários está condenada de antemão à esterilidade e ao fracasso.

Neste sentido, as maiores possibilidades de desenvolvimento da criança com história de deficiência encontram-se no campo das funçôes psicológicas superiores, cuja estruturação depende das suas relações sociais. $\mathrm{O}$ desenvolvimento incompleto das funçóes psíquicas superiores não está condicionado pela deficiência de modo primário, mas secundário e, portanto, é para este aspecto que todos os esforços educativos devem estar voltados, pois a deficiência secundária pode ser modificada.

Assim como para a medicina moderna o importante não é a enfermidade, mas o enfermo, para a defectologia o objeto não constitui a insuficiência em si, mas a criança acometida pela insuficiência. (...) Assim, a reação do organismo e da personalidade da criança ao defeito é o fato central e básico, a única realidade com que opera a defectologia. (Vygotski, 1997, p.14)

A partir das idéias de Adler, ${ }^{6}$ Vigotski desenvolve o conceito de compensação social, segundo o qual, a própria deficiência gera estímulos para sua superação. No entanto, diferentemente de Adler, considera que esta compensação não é natural, biológica, mas ela se dá nas e pelas relaçôes sociais.

O princípio da compensação pode ser explicado como aquele no qual o sujeito, criança ou adulto, envolve-se na vida social, coletiva e em processos 
que favorecem o desenvolvimento das atividades cognitivas superiores, independentemente dos problemas primários que marcam a história da pessoa. (Ros, 2000, p. 36)

Ao longo da história, e mais especificamente na modernidade, a cegueira tem sido considerada como uma deficiência, como uma falta, uma impossibilidade que vai gerar uma desvantagem em relação aos demais. Essa percepção da cegueira como deficiência tem como resultado uma relação focada no defeito, na não-possibilidade, o que acarreta preconceito e discriminação para com o cego e limita suas possibilidades reais de inclusão social.

O papel central que ocupa a linguagem na concepção de Vigotski (1996) sobre o desenvolvimento psíquico abre inúmeras possibilidades às pessoas com diferenças visuais, principalmente às pessoas cegas de nascimento. Vigotski afirma a possibilidade de a linguagem fornecer ao cego tudo de que ele necessita para conhecer o mundo, pois o conhecimento se dá fundamentalmente pela significação, que é da ordem do semiótico.

Vigotski (1997) desenvolveu a idéia de que a cegueira, assim como outras deficiências, pode promover uma reorganização completa no funcionamento psíquico, de modo a possibilitar uma compensação do impedimento. Enfatizou que o problema da cegueira é meramente instrumental, e ao se proporcionar ao cego formas alternativas de acesso aos aspectos da cultura inacessíveis a ele devido à ausência de visão, o problema será contornado, como no caso do sistema braile, que permite ao cego o acesso à linguagem escrita.

A fonte da compensação para o cego está na linguagem, na experiência social e na relação com os videntes. Por meio da linguagem o cego pode ter acesso às significações da cultura e participar das práticas sociais. Assim, as relações sociais são de fundamental importância para a criança cega superar o impedimento orgânico e seguir o curso de seu desenvolvimento cultural (Vygotski, 1997). O autor destaca a possibilidade que tem o cego de utilizar a vista de outra pessoa, a experiência alheia como instrumento para ver. A fonte da compensação para a pessoa com deficiência visual não seria, portanto, "o desenvolvimento do tato ou a maior sutileza do ouvido, mas a linguagem, quer dizer, a utilização da experiência social, a comunicação com os videntes" (1997, p. 107). 


\section{A percepção sobre suas características sensoriais}

Em um mundo eminentemente visual, as relações com a pessoa que apresenta uma ausência ou grave limitação nesse aspecto, geralmente são marcadas por esta característica - notadamente uma falta. Considera-se, assim, que a forma como a criança cega ou com baixa visão constrói sua identidade, nas e pelas relaçōes estabelecidas na família, na comunidade, na escola, no contato com os diversos profissionais, leva-a a perceber sua característica sensorial como uma condição limitadora, como uma condição negativamente diferente, ou ainda como uma condição potencialmente positiva, representada por habilidades, estratégias e diferentes esquemas construídos a partir da experiência não visual.

Ao realizar a análise dos depoimentos, chamou-nos a atenção a ênfase negativa presente nos depoimentos, com palavras como medo, vergonha, dificuldade, problema. Estas palavras aparecem com uma frequiência relativamente grande nos depoimentos e são usadas tanto para retratar situações negativas vivenciadas pelos sujeitos no ambiente escolar ou familiar, quanto para referirem-se as suas características sensoriais.

Apresentamos, a seguir, a freqüência de algumas destas palavras no depoimento dos sujeitos. Foram selecionadas as palavras difícil/dificuldade, problema, medo, vergonha, terrível/terror/horror, sozinho(a). Estas palavras foram consideradas negativas, pois, no contexto das falas dos sujeitos, aparecem relacionadas a lembranças de situações difíceis vividas pelos sujeitos.

\section{Quadro 1}

(Palavras utilizadas com maior freqüência nos relatos dos sujeitos)

\begin{tabular}{|c|c|}
\hline Palavras & Freqüência \\
\hline Difícil/dificuldade & 45 \\
problema & 19 \\
medo & 15 \\
vergonha & 12 \\
Terrível/terror/horrível & 12 \\
sozinho(a) & 11 \\
\hline Total & 114 \\
\hline
\end{tabular}

Fonte: Depoimentos com os sujeitos de pesquisa 
A ausência ou diminuição significativa da capacidade visual exige, da pessoa cega ou com baixa visão, a utilização de outros meios para estabelecer relações com os objetos, pessoas e coisas do mundo que a rodeiam. Esta condição se traduz em um processo perceptivo peculiar que, por sua vez, “(...) provoca uma reestruturação muito profunda de todas as forças do organismo e da personalidade" da pessoa (Vygotski, 1997, p. 99). Em nossa sociedade, a visão tem um papel preponderante nas relaçôes com o meio, já que boa parte da categorização da realidade tem por base este meio perceptivo, que é inacessível ou falho para a pessoa com diferenças visuais (Ocahita \& Rosa, 1995, p. 184). Essa relação entre ver e conhecer, ver e perceber é tão forte que, com relativa freqüência, substituem-se os verbos conhecer e perceber pelo verbo ver (por ex. quando solicitamos a alguém que apresente sua "visão" sobre determinado assunto ou situação).

Ao atribuir à visão um valor primordial, pode-se atribuir também à não-visão uma conotação marcadamente negativa ou excessivamente positiva. Exemplo disso são expressões como: "Cegueira de espírito" e "A verdadeira visão vem da alma”, qualificando a ausência da visão com um valor negativo (cego de espírito é o ignorante, a quem falta qualificação moral e intelectual) ou sobrenatural (a ausência de visão auxiliaria na real compreensão do bem e do mal, do certo e do errado, do que não pode ser enganado pelo olhar material).

Vigotski percebeu que as crianças com história de deficiência não têm consciência das suas particularidades como insuficiência perante o mundo, portanto não é a consciência do defeito que produz a compensação, mas "as dificuldades objetivas com que tropeça a criança no processo de desenvolvimento" (1997, p. 136), ou seja, a busca pela superação dos limites impostos pela cegueira, inclusive os limites sociais (acesso à educação, ao lazer, ao trabalho).

No entanto, nem sempre o enfrentamento dessas dificuldades resulta em uma compensação exitosa. Quando as relações são pautadas unicamente nas impossibilidades, quando as mediações não possibilitam aprendizagens que promovam os processos psicológicos superiores, o desenvolvimento da pessoa é organizado de tal forma a engendrar complicações secundárias tão fortes que passam a fazer parte do quadro de suas patologias e ajudam a defini-las (ex. alienação, comportamentos ritualísticos, dificuldades de socialização). 
Consideramos, também, as expressões envolvendo a palavra não: não sei/não sabia, não podia/não posso, não conseguia/não consigo, não queria/não quis, não tinha/não teve/não tivesse, não falava/ não perguntava/ não pedia, não foi/não era. Essas expressões foram evidenciadas na relação que apresentam com a dificuldade ou impossibilidade da ação do sujeito sobre o seu meio.

\section{Quadro 2}

(Expressões envolvendo a palavra não)

\begin{tabular}{|l|c|}
\hline \multicolumn{1}{|c|}{ Palavras } & Freqüência \\
\hline Não sei/não sabia & 46 \\
Não podia/não posso & 11 \\
Não conseguia/não consigo & 23 \\
Não queria/não quis & 17 \\
Não tinha/não teve / não tivesse & 37 \\
Não falava/não perguntava/ não pedia & 15 \\
Não foi/não era & 15 \\
\hline \multicolumn{1}{|c|}{ Total } & 164 \\
\hline
\end{tabular}

Fonte: Depoimentos dos sujeitos investigados

Após o levantamento da freqüência das expressões acima citadas, voltamos à leitura dos depoimentos para verificar se as mesmas estavam presentes proporcionalmente nos relatos dos três sujeitos, ou se algumas eram mais utilizadas por um ou outro sujeito, buscando-se, então, compreender quais eram os sentidos dados às expressóes por cada sujeito. Percebemos que a palavra problema aparece mais vezes (12) na fala de S1; difícil/dificuldade (18 vezes) e terrível/terror/horrível (12 vezes) na fala de S3; medo (9 vezes) e vergonha (11 vezes) na fala de S2.

No relato de $S 1$, a palavra problema aparece associada a sua condição visual e colocada na primeira pessoa (eu não conseguia acompanhar o pessoal devido ao problema de visão; a diretora não percebia o meu problema; o professor sabia do problema; meu problema era super complicado; só porque tenho problema; eu sempre comentava com os professores, dizia que tinha tal problema). Esse enfoque no problema como sendo seu ou em função de uma característica sua, retrata a forma 
como a pessoa com baixa visão é tratada pela sociedade e pela escola - a falta de visão é um problema (algo difícil de explicar ou resolver ${ }^{7}$ ) da pessoa que o tem, cabendo a ela adaptar-se ao mundo dos videntes. A palavra percorre todo seu relato, tanto quando se reporta a situaçóes vivenciadas no ensino fundamental, como no ensino superior, o que pode indicar que mesmo professores com uma formação mais ampla ainda consideram a baixa visão/cegueira como uma situação a ser resolvida por aquele que a possui.

$\mathrm{O}$ relato de $\mathrm{S} 3$, com muitas mençōes às situações difíceis, remete a uma história de solidão e falta de perspectivas. Sem poder contar com a compreensão dos que a cercavam sobre suas características sensoriais, S3 construiu de si mesma uma imagem de impossibilidades, marcada pela terrível sensação de não saber, de não conseguir, de não ter, ${ }^{8}$ já que assim era vista pelos outros. No entanto, essa situação foi sentida por S3 como algo que precisava romper a fim de conquistar uma posição de maior valor social: "Eu me dediquei muito a serviço doméstico porque eu tinha que fazer alguma coisa senão eu morria de tédio (S3P25). Mas eu já tava tão cansada, eu sabia que tinha que fazer alguma coisa, mas fazer o quê?? Era difícil” (S3P26).

Para Vigotski (1997, p. 104), "o sentimento de inferioridade, a insegurança e a debilidade surgem como resultado da valoração que o cego faz de sua posição". Como reação a esses sentimentos, a pessoa cega orienta sua ação para a superação. Ao tomar contato com a escrita em Braille, por intermédio de uma pessoa da comunidade onde morava, S3 pôde voltar a estudar e vencer o quadro de imobilidade em que se encontrou durante dez anos (desde o momento em que ficou cega até o retorno à escola).

Esse retorno não foi fácil nem destituído de grandes entraves ocasionados novamente pela percepção de que o indivíduo cego deve ser responsável pela superação das barreiras que a sociedade lhe impõe, já que foi sua opção "abandonar" a posição relativamente tranqüila da família ou da instituição especializada. São professores que não aceitavam modificar suas estratégias de ensino por considerar que todos devem aprender da mesma maneira (S3P36), a falta de materiais em braile (S3P33), a inacessibilidade física (S3P34), entre outras.

No entanto, nas partes finais que compóem seu depoimento, as palavras terrível/terror/horrível não se fazem mais presentes. Ao alcançar 
uma posição social mais valorada (estudante e depois professora) S3 pôde também refazer sua auto-imagem, agora não mais de uma pessoa inferior as demais, mas de uma pessoa que, com suas "diferenças", tem uma ação e uma posição social. A trajetória de S3 aponta para as dificuldades que a pessoa cega encontra para superar a situação de dependência e isolamento. Participar efetivamente da sociedade significa ter um emprego, se locomover independentemente, ter acesso a informações, enfim, ser considerado como uma pessoa total, não como alguém a quem falta algo, um ser incompleto.

As palavras mais presentes no relato de S2 são medo e vergonha e se referem ao ingresso dos entrevistados na escola. Ao ingressar na escola, S2 torna-se marcado pelas suas diferenças em relação aos demais alunos. Sua singularidade não é discutida, mas apresentada nas relaçóes com os adultos e crianças que fazem parte desse ambiente como alguma coisa negativa, que o torna inferior aos demais, gerando medo e vergonha, sentimentos esses estendidos às pessoas com quem convivia.

"Eu sempre deixei de fazer as coisas em função de passar por vergonha, constrangimento, essas coisas. Na verdade, o deficiente não passa por constrangimento, eu acho, a pessoa que está com ele passa, o irmão. Porque para ele [o deficiente] é natural. Eu sentia vergonha de mim, mas ficava constrangido pela pessoa que estava comigo" (S2P25).

Por que se sentir constrangido pelo outro? Segundo Goffman (1988), esse sentimento está ligado ao fato de os familiares serem "obrigados a compartilhar um pouco o descrédito do estigmatizado com o qual eles se relacionam" (p. 20). Não discutir a questão da sua condição visual em casa e na escola não permite a criança entender suas características e suas diferenças de apreensão das coisas a sua volta, ficando, assim, constantemente constrangida, envergonhada com o que ela pensa ser "uma maneira errada" de relacionar-se com o mundo.

Diversos momentos do depoimento de S2 deixam evidente a sensação de medo e de vergonha vivenciadas em diferentes momentos de sua trajetória escolar (S2P4, S2P18, S2P19, ${ }^{9}$ S2P25, S2P26 ${ }^{10}$ ), apontando a relação desses sentimentos com a condição de impossibilidade e, principalmente, de dependência vivenciadas pela pessoa com diferenças visuais: "Sempre tive muita vergonha. Muita vergonha, muita vergonha. De pedir ajuda, das pessoas olharem pra mim, de tudo. A vergonha prejudicou bastante eu acho" (S2P18). 
S2 pontua, em seu relato, o que considera ser a justificativa para a negação da pessoa cega de suas características sensoriais e que o distingue dos demais: a necessidade de se enquadrar na "normalidade": "Por que o deficiente, enquanto não se encontra, sempre quer passar por normal. Quando vê um deficiente dizendo que devem ter com ele atitudes de pessoa normal é porque ainda tem um pouquinho de dificuldades de aceitação, eu acho né" (S2P4).

A aceitação de suas singularidades em relação aos demais não é tão facilmente assumida, pois requer uma percepção de si mesmo como um ser completo, integral, percepção esta que só pode ocorrer quando o sujeito vivencia experiências de valoração positiva de suas capacidades.

$\mathrm{O}$ acesso ao ensino superior parece contribuir para a constituição de relaçôes interpessoais mais tranqüilas, onde não aparecem mais situações em que o sujeito se sinta envergonhado de suas características. Ao contrário, aponta suas necessidades de apoio em alguns momentos, mas não como uma dependência do outro. Esse apoio está muito mais relacionado à falta de recursos/materiais especializados, o que lhe permitiria realizar as atividades acadêmicas de forma mais autônoma.

\section{Algumas considerações}

A criança cega pode perfeitamente se apropriar das significações de seu meio e participar das práticas sociais, pois dispõe do instrumento necessário para isso - a linguagem. Além disso, a concepção de que, com o desenvolvimento das funçóes psíquicas superiores, o homem transforma sua relação com o mundo e nela introduz a dimensão semiótica, minimiza a dimensão da perda decorrente da cegueira.

Vigotski (1997), em seus escritos sobre a educação das pessoas cegas, critica a perspectiva segundo a qual se busca suprir, por meio de outras vias, a falta de representaçóes visuais sobre a realidade externa. Para o autor, tal perspectiva teórica considera a substituição das imagens visuais por sensaçôes de outro tipo, sem compreender que é impossível a substituição concreta. Segundo o autor, pela via das percepções e das representações concretas, ou seja, dos processos elementares, nunca se criará a possibilidade de substituição das imagens espaciais que faltam ao cego. Vigotski afirma que a verdadeira esfera da compensação das conseqüências da cegueira é a dos conceitos, ou seja, a esfera das funções psíquicas superiores. 
Em uma concepção de deficiência que percebe o sucesso/ insucesso da pessoa com história de deficiência como determinado pelas condiçóes sociais do indivíduo, pelas relações que ele estabelece e que são estabelecidas com ele ao longo de sua vida, pode-se dizer, nas palavras de Vigotski (1997, p. 44 e 45) que "o que decide o destino da personalidade, em última instância, não é o defeito em si, mas suas conseqüências sociais, sua realização sociopsicológica”.

Ao atribuir papel central às relaçôes sociais e à linguagem no desenvolvimento das funçôes psíquicas superiores, a teoria histórico-cultural permite que se compreenda a problemática da cegueira sob um ponto de vista otimista no que se refere às possibilidades de desenvolvimento das crianças cegas, desde que estejam imersas na cultura e participem das práticas sociais. Embora as experiências iniciais dos sujeitos retratados neste trabalho tenham sido difíceis, foram essas experiências que criaram a necessidade de compensarem/superarem as limitaçôes sociais impostas pela sua diferença. Ao assumirem papéis sociais mais visíveis, mais atuantes, a marca da diferença deixa de ser negativa e passa a ser uma característica que define espaços de atuação e valoração.

\section{Recebido em março de 2008 e aprovado em julho de 2008.}

\section{Notas}

1. Empregamos, neste trabalho, a grafia do nome do autor Vigotski, mas indicaremos outras grafias nas citações e referências, de acordo com as fontes bibliográficas.

2. Ciência que estudava crianças com vários tipos de problemas mentais e físicos.

3. Neste texto, optamos por utilizar os termos presentes nos escritos de Vigotski, mesmo que estes sejam atualmente considerados inadequados para se referir à criança/pessoa com diferentes características.

4. As funções psicológicas elementares são de origem biológica (como reaçôes automáticas, reflexos e associaçōes simples), imediatas, involuntárias.

5. Pensamento em conceitos, linguagem racional, memória lógica, atenção voluntária etc.

6. Para a escola de Alfred Adler (1870-1937), qualquer deficiência acarretaria uma compensação psicológica, ou em alguns casos até uma supercompensação. O sentimento de inferioridade causado pelas conseqüências sociais dessa deficiência e da reflexão que o sujeito faz a respeito de sua condição torna-se gatilho desses mecanismos compensatórios.

7. Segundo o Novo Dicionário Aurélio da Língua Portuguesa, esta é uma das definições da palavra problema. Considerou-se a mais adequada neste caso, pois a sociedade (aqui representada pela família e escola) ainda trata a pessoa com diferenças visuais como um ser invisível, não considerada nos momentos de tomada de decisôes. 
8. Em seu relato aparece 37 vezes a expressão não sei/não sabia, 14 vezes não conseguia/não consigo e 17 vezes não tinhalnão tive, conforme quadro anexo.

9. “O meu irmão já tinha reprovado e eu sabia que ia estudar na sala dele, ele até me ajudou, encadernou os cadernos, mas não me convencia. Nada convence quando a gente tem medo. Bem no começo assim, o ambiente, a gente se sentia um peixe fora d'água..." (S2P19).

10. “(...) Porque eu não falava da minha dificuldade, nunca falei pra ninguém, nunca conversei isso com ninguém, o que eu passava, se precisava de ajuda, nunca, nunca. Eu brincava normal, tudo que eles [as crianças] faziam eu tentava fazer igual, andar de bicicleta... Esbarrei muito de bicicleta, mas dizia que faltou freio, mas nunca que era porque eu não via. Eu tinha vergonha de dizer que eu não via" (S2P26).

\section{Referências}

AMIRALIAN, M.L.T.M. Compreendendo o cego: uma visão psicanalítica da cegueira por meio de desenhos-histórias. São Paulo: Casa do Psicólogo, 1997.

BELARMINO, J. Associativismo e política: a luta dos grupos estigmatizados pela cidadania plena. João Pessoa: Idéia, 1996.

BRASIL. Lei n. 9394/96. Diário Oficial da Uniāo. Brasília, DF, 20 de dezembro de 1996.

BRASIL. Portaria n. 3.284, de 7 de novembro de 2003. Disponível em: <http:// www.mec.gov.br>. Acesso em: 22 out. 2004.

BRUNO, M.M.G.; MOTA, M.G.B. Programa de Capacitação de Recursos Humanos do Ensino Fundamental: deficiência visual vol. 1 fascículos I - II - III. Brasília, DF: Ministério da Educação, Secretaria de Educação Especial, 2001.

BUENO, J.G.S. Educação especial brasileira: integração/segregação do aluno diferente. 2. ed. São Paulo: EDUC, 1999.

FREIRE, I.M. Um olhar sobre a diferença: interaçóes e experiências dos adultos com a criança não-visual. In: Bianchetti, L., Freire, I. M.(Org.). Um olhar sobre a diferença: interação, trabalho e cidadania. 3. ed. Campinas: Papirus, 1998. p.135-180.

GIL, M. Deficiência visual. Cadernos da TV Escola. Brasília: MEC/Secretaria de Educação a distância, 2000. 
A pessoa cega e a inclusão: um olhar a partir da psicologia histórico-cultural

LIRA, M.C.F. Lembranças de escola: um estudo sobre a inclusão do aluno com diferenças visuais. 2005. Dissertação (Mestrado) - Universidade do Vale do Itajaí, Itajaí.

MARTÍN, M.B.; BUENO, S.T. Deficiente visual e acção educativa. In: BAutista, R. Necessidades educativas especiais. Lisboa: Dinalivro, 1997.

MARTÍN, M.B. Visão normal. In: Martín, M.B.; Bueno, S.T. (Coord.). Deficiência visual: aspectos psicoevolutivos e educativos. Trad. Magali de Lourdes Pedro. São Paulo: Livraria Santos, 2003. p. 27-44.

NERI, M. et al. Retratos da deficiência no Brasil. Rio de Janeiro: FGV; IBRE; CPS, 2003.

OCAHITA, E.; ROSA, A. Percepção, ação e conhecimento em crianças cegas. In: Coll, C.; Palacios, J.; Marchesi, A. Desenvolvimento psicológico e educação: necessidades educativas especiais e aprendizagem escolar. Trad. Marcos A.G. Domingues. Porto Alegre: ARTMED, 1995. p.183-197. V. 3.

ROS, S.Z. Vivendo e aprendendo: processos de mudança em grupos marginalizados pela "deficiência" e pela velhice "incapacitada". Ponto de Vista, Florianópolis, v. 2, n. 2, p. 34-40, 2000.

SANTA CATARINA, Fundação Catarinense de Educação Especial. Avaliação do processo de integração de alunos com necessidades especiais na rede estadual de ensino de Santa Catarina no periodo de 1988 a 1997. São José: FCEE, 2002. 248p.

UNESCO. Declaração de Salamanca. Disponível em: <http:// www.entreamigos.com.br/textos/salamanca/htm>. Acesso em: 20 abr. 2002.

VAN DER VERR, R.; VALSINER, J. Vygotsky, uma sintese. Trad. Cecília C. Bartalotti. São Paulo: Loyola, 1996.

VYGOTSKI, L.S. Obras escogidas. Tomo V. Fundamentos de defectologia. Cuba: Editorial Pueblo y Educación, 1989.

VYGOTSKI, L.S. Pensamento e Linguagem. 6. ed. São Paulo: Martins Fontes, 1996.

VYGOTSKI, L.S. Obras escogidas: V. Fundamentos de defectologia. Madrid: Visor, 1997. 